\title{
Development of Molecularly Imprinted Polymers - from Environmental Sensors to Biotechnology Applications
}

\section{Edward P.C. Lai*}

Department of Chemistry, Carleton University, Canada

Many researchers have concentrated on the development of new methods for rapid determination of endocrine disrupting chemicals (EDCs) that are widely detected in environmental waters. Exposure to EDCs is associated with an earlier onset of puberty, decreased fecundity or fertility, altered sexual behavior, and increased incidence of abnormalities or cancers of the reproductive tract in humans [1]. The findings of a new study suggest that some endocrine disruptors may play a role in the obesity epidemic [2]. Direct determination of EDCs in water remains a challenging problem due to their low concentrations (ng/L to $\mu \mathrm{g} / \mathrm{L}$ ), which is further complicated by the presence of numerous other compounds (pharmaceuticals, personal care products, detergents and natural organic matter). Such matrix effects are formidable even when sophisticated instrumental techniques are used $[3,4]$

Considerable efforts have been focused on the synthesis of molecularly imprinted polymer (MIP) particles that specifically recognized estrogenic compounds. MIPs represent a class of smart materials that have artificially created receptor cavities to mimic biological antibodies. Researchers can imprint a plastic material to create molecularly sized and shaped cavities with specific interactions to bind the target analyte [5]. MIPs show outstanding affinity towards the analyte in aqueous solution, with a binding capacity as high as $300 \mathrm{mg} / \mathrm{g}$. They can be used as sorbent materials in solid-phase extraction (SPE) for the quantitative enrichment of analytes in environmental water samples prior to determination by an instrumental method. Removal of interfering matrix constituents frequently extends the detection limit and improves the accuracy of trace analysis. The structural dimension of MIPs can influence partition kinetics, as both submicro- and nanoparticle sizes have demonstrated improvements in analyte recovery. MIPs can be synthesized for several natural and synthetic EDCs such as estrone (E1), 17 $\alpha$-estradiol ( $\alpha$-E2), $17 \beta$-estradiol ( $\beta$-E2), estriol (E3), $17 \alpha$-ethynylestradiol (EE2) and bisphenol A (BPA), among which $\beta$-E2 exhibits the strongest estrogenic potency (EC50 $0.015 \pm 0.002 \mathrm{nM}$ ) [6]. They have been applied in different kinds of electrochemical sensors [7-11] and optical sensors [12,13].

Currently there is no commercial availability of online sensors that are suitable for monitoring EDCs rapidly and cost-effectively. Neither in-line immunosensor nor chromatography would be ideal as they have high costs and maintenance requirements. EDCs at ultratrace levels in environmental water can be determined by selective pre-concentration using the molecular recognition property of MIP particles. After preconcentration, the extract can be quantitatively analyzed by spectrofluorometry, capillary electrophoresis and liquid chromatography-tandem mass spectrometry [14]. However, efforts will be required to optimize various parameters such as washing solvent, elution solvent and breakthrough volume to reduce non-specific interactions during the selective preconcentration of EDCs from water samples. A novel sensing scheme based on fluorescence quenching of $17 \beta$-estradiol (E2) was recently reported. Fluorescence emission from E2 non-specifically bound onto the MIP was first quenched by gold nanoparticles. Next nitrite anions penetrated the porous MIP structure to quench the fluorescence emission from E2 molecules specifically bound inside imprinted cavities. The difference between these two emission intensities varied with the initial E2 concentration in water from 0.1 to $10 \mathrm{ng} / \mathrm{mL}$ [15]. One major advantage of this method is the high selectivity of MIP particles for E2 [16] over dissimilar structures [17]. Rapid screening of E2 in water takes only $10 \mathrm{~min}$.

In field studies, ultra-trace EDCs can be more efficiently preconcentrated by flowing 100-1000 $\mathrm{mL}$ of water through an optical cell packed with MIP particles. Flow injection analysis (without coupling to a HPLC system) is possible by automated sequential injections of AuNPs and sodium nitrite to make the fluorescence quenching measurements. A detection limit of $15 \mathrm{ng} / \mathrm{L}$ will attest to its suitability for rapid field analysis. Although MIP particles tend to suffer from biofouling, they are so simple in design and so cost effective in synthesis to be disposable after a single use. As these optical sensors have operational characteristics similar to a $\mathrm{pH}$ sensor in terms of durability, selectivity and concentration range, they will be suitable for autonomous, realtime data acquisition in a closed loop system at low maintenance costs. For EDCs which are not inherently fluorescent, quenching of the fluorescence from an indicator probe would be a feasible modification of the above measurement principle. These two options potentially will allow a suite of EDC sensors to be developed for benzophenone, dichlorodiphenyldichloroethylene, dienestrol, diethylstilbestrol, ditert-butyl-benzoquinone, hexachlorobenzene, hexachlorocyclohexane, mestranol, nonylphenol, nonylphenol monoethoxylate carboxylate, oxychlordane phenanthrene, progesterone and triclosan.

The selectivity of a new MIP for 3-nitro-l-tyrosine, an oxidative stress marker associated with neuro-degenerative disorders, was demonstrated in human urine analysis [18]. Another MIP was developed for the SPE of irinotecan from human serum [19]. The fingerprint analysis concept, which distinctively identifies a pool of peptides composing a protein, was recently developed for the rational preparation of MIPs for protein recognition [20]. From environmental sensors to biotechnology applications, the diversity of areas and complexity of systems are both indicating numerous opportunities in the near future.

*Corresponding author: Edward P.C. Lai, Department of Chemistry, Carleton University, 1125 Colonel By Drive, Ottawa, Ontario K1S 5B6, Canada, E-mail: edward lai@carleton.ca

Received September 24, 2012; Accepted September 24, 2012; Published September 29, 2012

Citation: Lai EPC (2012) Development of Molecularly Imprinted Polymers - from Environmental Sensors to Biotechnology Applications. J Pet Environ Biotechnol 3: e113. doi:10.4172/2157-7463.1000e113

Copyright: (C) 2012 Lai EPC. This is an open-access article distributed under the terms of the Creative Commons Attribution License, which permits unrestricted use, distribution, and reproduction in any medium, provided the original author and source are credited. 
Citation: Lai EPC (2012) Development of Molecularly Imprinted Polymers - from Environmental Sensors to Biotechnology Applications. J Pet Environ Biotechnol 3: e113. doi:10.4172/2157-7463.1000e113

\section{References}

1. Pelch KE, Beeman JM, Niebruegge BA, Winkeler SR, Nagel SC (2011) Endocrine-disrupting Chemicals (EDCs) in Mammals. Hormones \& Reproduction of Vertebrates 329-371.

2. Tang-Péronard JL, Andersen HR, Jensen TK, Heitmann BL (2011) Endocrinedisrupting chemicals and obesity development in humans: a review. Obes Rev 12: 622-636.

3. Zhang HC, Yu XJ, Yang WC, Peng JF, Xu T, et al. (2011) MCX based solid phase extraction combined with liquid chromatography tandem mass spectrometry for the simultaneous determination of 31 endocrine-disrupting compounds in surface water of Shanghai. J Chromatogr B Analyt Technol Biomed Life Sci 879: 2998-3004.

4. Kibbey TCG, Chen L, Singhaputtangkul N, Sabatini DA (2009) A UV-transparen passive concentrator/spectrum deconvolution method for simultaneous detection of endocrine disrupting chemicals (EDCs) and related contaminants in natural waters. Chemosphere, 76: 1249-1257.

5. Moein MM, Javanbakht M, Akbari-adergani B (2011) Molecularly imprinted polymer cartridges coupled on-line with high performance liquid chromatography for simple and rapid analysis of dextromethorphan in human plasma samples. $J$ Chromatogr B Analyt Technol Biomed Life Sci 879: 777-782.

6. Frizzella C, Ndossib v, Verhaegenb S, Dahlb E, Eriksend G, et al. (2011) Endocrine disrupting effects of zearalenone, alpha- and beta-zearalenol at the level of nuclear receptor binding and steroidogenesis. Toxicol Lett 206: 210217

7. Alizadeh T, Akhoundian M (2010) A novel potentiometric sensor for promethazine based on a molecularly imprinted polymer (MIP): The role of MIP structure on the sensor performance. Electrochimica Acta 55: 3477-3485.

8. Zhang J, Wang YQ, Lv RH, Xu L (2010) Electrochemical tolazoline sensor based on gold nanoparticles and imprinted poly-o-aminothiophenol film. Electrochimica Acta 55: 4039-4044.

9. Patel AK, Sharma PS, Prasad BB (2010) Trace-level sensing of creatine in real sample using a zwitterionic molecularly imprinted polymer brush grafted to sol-gel modified graphite electrode. Thin Solid Films 518: 2847-2853.

10. Yuan L, Zhang J, Zhou P, Chen J, Wang R, et al. (2011) Electrochemical sensor based on molecularly imprinted membranes at platinum nanoparticles-modified electrode for determination of $17 \beta$-estradiol. Biosensors \& Bioelectronics 29 : 29-33.
11. Gholivand MB, Karimian N, Malekzadeh G (2012) Computational design and synthesis of a high selective molecularly imprinted polymer for voltammetric sensing of propazine in food samples. Talanta 89: 513-520.

12. Wu N, Feng L, Tan Y, Hu J (2009) An optical reflected device using a molecularly imprinted polymer film sensor. Anal Chim Acta 653: 103-108.

13. Prasad BB, Tiwari MP, Madhuri R, Sharma PS (2010) Development of a highly sensitive and selective hyphenated technique (molecularly imprinted microsolid phase extraction fiber-molecularly imprinted polymer fiber sensor) for ultratrace analysis of folic acid. Anal Chim Acta 662: 14-22.

14. Kowalski D, Poboży E, Trojanowicz M (2011) Flow-Injection Preconcentration of Chloramphenicol Using Molecularly Imprinted Polymer for HPLC Determination in Environmental Samples. Journal of Automated Methods \& Management in Chemistry, 143416.

15. Yang Y, Lai EPC (2011) Optimization of Molecularly Imprinted Polymer Method for Rapid Screening of $17 \beta$-Estradiol in Water by Fluorescence Quenching International Journal of Analytical Chemistry, 214747.

16. Yang Y, Lai EPC, Liu M (2010) Spectroscopic Analysis of Poly (Methacrylic Acid-co-Ethylene Glycol Dimethacrylate) Submicron Particles by Fluorescence Emission and Light Scattering upon Binding with $17 \beta$-Estradiol in Water Treatment. The Open Colloid Science Journal 3: 1-8.

17. DeMaleki Z, Lai EPC, Zlotorzynska ED (2010) Capillary electrophoresis characterization of molecularly imprinted polymer particles in fast binding with 17ß-estradiol. J Sep Sci 33: 2796-2803.

18. Mergola L, Scorrano S, Del Sole R, Lazzoi MR, Vasapollo G (2012) Developments in the synthesis of a water compatible molecularly imprinted polymer as artificial receptor for detection of 3-nitro-I-tyrosine in neurological diseases. Biosens Bioelectron.

19. Roy B, Duy SV, Puy JY, Martin C, Guitton J, et al. (2012) Synthesis and Evaluation of a Molecularly Imprinted Polymer for Selective Solid-Phase Extraction of Irinotecan from Human Serum Samples Journal of Functional Biomaterials 3:131-142.

20. Bossi AM, Sharma PS, Montana L, Zoccatelli G, Laub O, et al. (2012) Fingerprint-imprinted polymer: rational selection of peptide epitope templates for the determination of proteins by molecularly imprinted polymers. Anal Chem 84: $4036-4041$. 